\title{
Effective Modulus Estimation Method of QT400-18 Cast Iron with Repair Welding
}

\author{
Tao Wei $\mathbb{D}^{1,2}$ Wei Liu $\left(\mathbb{D},{ }^{1}\right.$ Wenxuan Gou, ${ }^{1}$ and Junqiang Kou $\mathbb{D}^{2}$ \\ ${ }^{1}$ School of Mechanics, Civil Eng. \& Architecture, Northwestern Polytechnical University, Xi'an 710129, China \\ ${ }^{2}$ Northwest Industries Group Co., Ltd., Xi'an 710043, China \\ Correspondence should be addressed to Wei Liu; liuwei@nwpu.edu.cn
}

Received 14 May 2019; Accepted 22 August 2019; Published 19 September 2019

Academic Editor: Hervé Laurent

Copyright (C) 2019 Tao Wei et al. This is an open access article distributed under the Creative Commons Attribution License, which permits unrestricted use, distribution, and reproduction in any medium, provided the original work is properly cited.

Repair welding is an important remediation process for castings with slight defects. In this paper, the tensile behaviors of the QT400-18 nodular cast iron with different repair welding sizes were experimentally analyzed. Specimens with different diameters of the filler region were prepared by the same welding process. The fracture initiated in the filler region under uniaxial tensile loading. The modulus, strength, and ductility decreased with the weld diameter increase. The postyield hardening phenomenon was not observed in the repaired specimen. The repair region ratio was defined as the proportion of the repair welding area to the cross-sectional area of the structure. The effective modulus of the repaired specimens decreased with the repair region ratio increase, and the relationship between them was fitted by a negative exponential function. The repair welding region was treated as an inclusion in the matrix of castings, and the volume fraction of inclusion was applied to characterize the repair welding size. Based on the theories of Eshelby tensor and Mori-Tanaka equivalent method, a method for estimating macroscopic effective modulus of repair welding castings was established. The theoretical solutions were in good agreement with the experimental results. The method will be helpful in estimating the safe service limit of repair welded castings.

\section{Introduction}

Some foundry minor defects, such as gas pores, shrinkage porosity, and misrun, exist in large castings more or less [1-3]. Repair welding is an important restoring technique to extend these slightly defected castings' service life [4-6]. High cost of large casting makes the repair welding method very desirable since castings with minor defects can be repaired rather than culled to afford continual use. However, many factors affect the validation of repair welding, such as chemical components, welding process, and welding size. Therefore, establishing an effective mechanical performance prediction method is important for casting engineering.

The equivalent mechanical behaviors of repair welds have always been a research focus in foundry industry. For some materials, such as cast Ti-6Al-4V and Titanium castings, minor weld repair was demonstrated acceptable for creep $[7,8]$, and fatigue cracks initiated from the base metal in the high-cycle fatigue load case $[9,10]$. Smith $[11]$ derived the equations of strain fields around a cruciform crack in the repair welding region, and the relation between the weld stress pattern and the crack driving force was established. Zhang et al.'s [12] results showed that the Vickers hardness was affected by the microstructures of the heat-affected zone, but the fatigue crack growth rate was slightly influenced.

However, the situation also depends on the material, loading conditions, and welding process. The weld defects were introduced in the vicinity of the weldment by an unqualified welding process accidentally, and fatigue cracks initiated from these defects. The microcracks at the welded junctions evolved into subsequent macrocracks in the tensile or cyclic loading [13]. The micromechanical approach was applied to determine the mechanism of crack initiation and propagation in weldments [14]. Venugopal et al. [15] found that repair welding may also further deteriorate the microstructure, and corrosion preferred to locate along the partially melted zone. Katsas et al. [16] pointed out that the influence of the change of the welded microstructure was important on mechanical properties. The repair welding process significantly increased the grain size and size of 
defects in the HAZ [17]. Durmus [18] compared the mechanical properties of the specimens welded with different filler metals by metallographic analysis. Nascimento and Voorwald [19] carried out the fatigue crack growth tests in the base material, heat-affected zone, and filler metal of tungsten inert gas (TIG) repair welding, and the results indicated that the TIG method increased the fracture resistance in the weld metal but decreased it in the HAZ after repair and that microhardness and microstructural changes played important roles in the crack propagation of repair welded casting. In summary, the effectiveness of repair welding seems to be ambiguous, the problem is complex, and repair welding depends on several macro- or microfactors such as size, shape, welding process, microstructure, and morphology. Some more experimental data and their mechanical empirical models should be provided.

In this paper, the influence of repair welding on the effective stiffness performance was investigated. Tensile tests for QT400-18 nodular cast iron specimens with different repair welding sizes were carried out. The relations between the effective modulus and the repaired size were discussed. A prediction method of effective modulus for repair welded casting was proposed. This work is helpful to validate repair welded casting structures.

\section{Experimental Procedure}

2.1. Materials. QT400-18 (ISO: 400-18) nodular cast iron was applied as the base material in this study. This material is often made for the cylinder block, cover, crankshaft, etc. in heavy diesel engines. Z308 (corresponding to the AWS standard ENi-CI, alkaline-coated electrode, and HRC: HB150) was used for repair welding on QT400-18 nodular cast iron. The diameter of the Z308 electrode cored wires was $3.2 \mathrm{~mm}$. The chemical compositions (wt.\%) of the two materials are presented in Table 1.

2.2. Repair Welding Specimen. For the QT400-18 material, foundry defects often existed in the terminal stage of solidification, and some of these defects in casting were exposed after some machining processes. In practice, the whole portion of shrinkage porosity (if any) was hollowed out from the base material manually, and then the repair welding process was carried out to fill in the hollowed parts. Usually, the perforated defect was more harmful to the structure; special care should be paid to the perforated forms of foundry defects. Therefore, in this study, the perforated welding specimen was manufactured.

Furthermore, in order to investigate the influence of repairing size on effective mechanical performance, a certain amount of repair welding specimens in the same process batch were required, but the repairing sizes were different.

The specimens with different repair welding sizes were prepared by the following procedures:

(1) As shown in Figure 1, a QT400-18 rectangular ingot was firstly manufactured, and the dimensions were $180 \mathrm{~mm} \times 45 \mathrm{~mm} \times 60 \mathrm{~mm}$.
TABLE 1: Chemical compositions of QT400-18 and Z308 (wt.\%).

\begin{tabular}{lcccccccc}
\hline & $\mathrm{C}$ & $\mathrm{Si}$ & $\mathrm{Mn}$ & $\mathrm{S}$ & $\mathrm{P}$ & $\mathrm{Mg}$ & $\mathrm{Ni}$ & $\mathrm{Fe}$ \\
\hline QT400-18 & 3.61 & 2.56 & 0.47 & 0.018 & 0.047 & 0.045 & & \\
Z308 & $\leq 2.0$ & $\leq 2.5$ & $\leq 1.0$ & $\leq 0.03$ & & & $\geq 90$ & $\leq 8$ \\
\hline
\end{tabular}

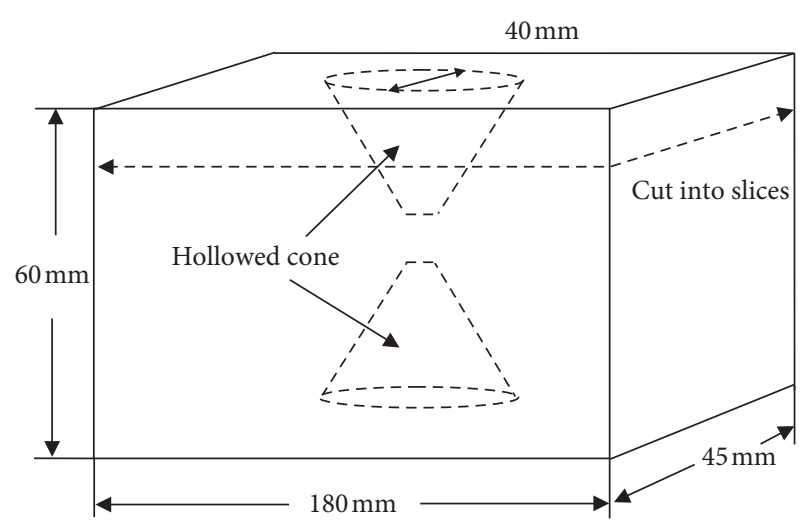

Figure 1: Schematic diagram of repair welding specimen preparation.

(2) The rectangular castings were hollowed by two symmetric frustum cones at the center site (in the top and the bottom surface, respectively). The angle of the cone was $60^{\circ}$, and the maximal diameter of cones was $40 \mathrm{~mm}$. The two cones should not penetrate the ingot, as shown in Figure 1.

(3) The hollowed cone was polished to eliminate the influence of impurities, to ensure that there were no cracks or other defects. Also, residual stress was relieved through the method of hammering in the sides of the hollowed region.

(4) Temperature gradient may result in cold cracks; therefore, local preheating was carried out on the hollowed parts of the ingot before welding, and the welding electrode was also preheated. The welding processes of "layers and intervals" were carried out; that is, a small amount of new consumables were added upon the previous layer, and then the new filled metal was solidified with hammering. The above processes were repeated until the hollowed cone was fulfilled.

(5) Manual argon-arc welding was carried out to fill the hollowed regions. The mode of welding power supply was DC, and the welding current was set to $60 \mathrm{~A}$. Considering that residual stress may be introduced in the case of the large volume welding, the short arc welding process was carried out. In this method, the two symmetric frustum cones were fulfilled by several overlaps rather than once entirely welded, and the thickness of each overlap was about $3 \mathrm{~mm}$. After the previous overlap was entirely solidified, in this pause, the residual stress was released by hammering the weld bond.

(6) The repaired rectangular castings were cut into slices in the transverse direction after the repair region 
completely solidified in room temperature, and then the repaired welding area was located in the center of every plate (Figure 2). By this way, a series of plates with different repaired fractions in the cross section can be obtained.

(7) Each plate was then made into the flat specimen. The geometry of the specimen with a repaired weld is shown in Figure 2. The gauge length of the specimen was $50 \mathrm{~mm}$.

The size of the repaired filler region was measured by the mean diameter as follows:

$$
D=\frac{d_{1}+d_{2}}{2}
$$

where $D$ is the mean diameter of the repaired welding and $d_{1}$ and $d_{2}$ are the diameter of two surfaces of each specimen, respectively (as shown in Figure 3). The mean diameters of the filler region in the specimens were $6.9 \mathrm{~mm}, 15.2 \mathrm{~mm}$, $25.8 \mathrm{~mm}$, and $30.0 \mathrm{~mm}$, respectively; here, the filler region of the specimen with the welding diameter of $30 \mathrm{~mm}$ occupied the whole width of the gauge section.

2.3. Uniaxial Tensile Tests. In order to compare the performance before and after repair welding, intact specimens (without defect or welding repair) of the QT400-18 material were prepared with the same dimensions. Uniaxial tensile tests were carried out on the Instron 8802 servo hydraulic universal machine at room temperature. The displacement loading rate was $2 \mathrm{~mm} / \mathrm{min}$. The strain data of the gauge length were obtained by an MTS extensometer. The nominal stress was defined as the loading divided by the original cross-sectional area of the specimen.

\section{Results and Discussion}

3.1. Tensile Results. The stress-strain responses of the intact specimen and specimen with the welding diameter of $30 \mathrm{~mm}$ under uniaxial tensile loading are shown in Figure 4. The fracture strain of the intact specimen was about 0.022 , and the fracture strain of the repaired specimen with the welding diameter of $30 \mathrm{~mm}$ was about 0.014 . The ductility of the material weakened after repair welding.

The phenomenon of the fracture initiating in the filler region was observed in all specimens (Figure 5). The filler metal reached the yield phase earlier than the base material, and the crack first nucleated in the filler material. Therefore, the properties' consistency between the filler and the base material was a key factor for improving the fracture resistance of repair welded structures. (The original purpose of the strain gauge was to monitor the stresses on the base and filler materials, but the fracture initiated in the filler region and destroyed the strain gauge, as shown in Figure 5. Therefore, the nominal stress was adopted in this paper, and the data by the strain gauge were not used.)

Figure 6 shows fracture behaviors of the intact specimen and the repair welding specimens with different weld diameters. For the welding-repaired specimen, the fracture occurred at the maximal stress point without any obvious plastic deformation. The postyield hardening phenomenon was not observed after repair welding. This was the main reason for the reduction of failure strain.

The trends of elastic modulus, tensile stress, and failure strain with weld diameters are shown in Figure 7. Compared with the tensile characteristics of the intact specimen, both strength and capability of ductility weakened after repair welding. The effective modulus (slope of the linear segment), failure strain, and strength decreased with the repair welding size increase. The failure strain decreased sharply after repair welding (Figure 7(b)). The effective modulus and failure strength of the specimen with a welding diameter of $30 \mathrm{~mm}$ reduced to about $50 \%$ (Figures $7(\mathrm{~b})$ and $7(\mathrm{c})$ ). Therefore, effective mechanical modulus estimation was important for repaired casting application.

In this paper, the welding repair region ratio $v=D / D_{0}$ was introduced to characterize the relative welded size on the cross section, where $x_{j}$ is the width of the gauge section of the specimen (in this study, $\left\{\begin{array}{l}\sigma^{0}=1 / V \int_{\Omega} \sigma_{i} d V \\ \varepsilon^{0}=1 / V \int_{\Omega} \varepsilon_{i} d V\end{array}\right)$. The relation of effective modulus $E$ of the welded specimen with the repair region ratio can be fitted by a negative exponential function as follows:

$$
E=\left(k \cdot e^{-(v / m)}+b\right) E_{0},
$$

where $E_{0}$ is the elastic modulus of the intact specimen (without defect or welding repair); $b, k$, and $m$ are material parameters, and their values can be obtained by calculations of least square fitting, which were $0.48,0.52$, and 0.32 , respectively.

The fitted model (2) could be simplified as follows:

$$
E=\frac{\left(e^{-3 v}+1\right)}{2} E_{0} \text {. }
$$

The experimental data and predictions by formulas (2) and (3) are displayed in Figure 8. The descending rate of the effective modulus via the repaired region ratio $v$ could be obtained:

$$
\frac{d E}{d v}=-\frac{3 E_{0}}{2} e^{-3 v}
$$

The effective modulus of repaired cast iron decreased with the repaired region ratio according to the rule of negative exponent.

\section{The Equivalent Inclusion Method}

In order to study the equivalent model of the effective modulus for repair welding casting, a representative volume element (RVE) model was abstracted from the welding-repaired casting, as shown in Figure 9. The RVE included a part of repair welding and the matrix of the casting.

The RVE model was deemed as an infinite elastic body containing inclusions, and its elastic field was quantified by the Eshelby equivalent inclusion theory [20]. The theory assumed that the loading-deformation behavior of the material with inclusions was equal to that of a uniform 

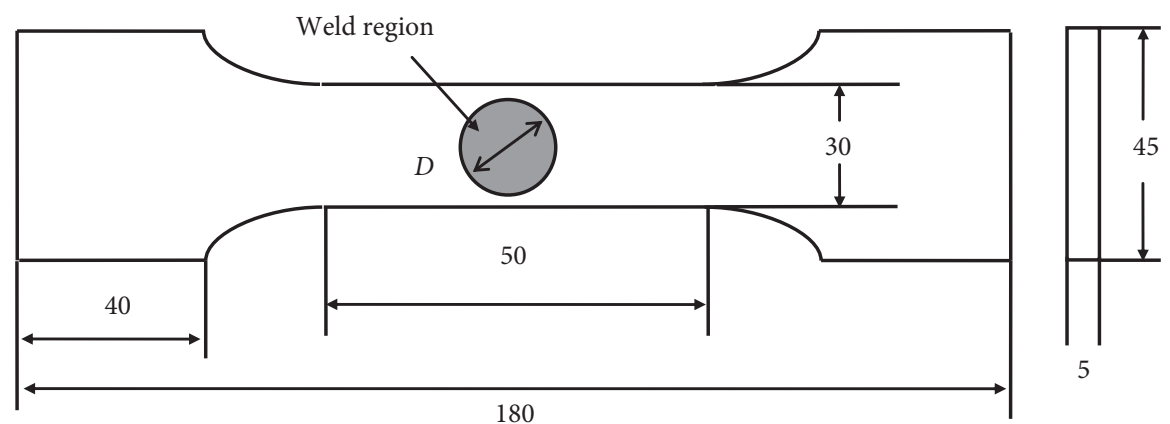

Figure 2: Shape and dimensions of the repaired welding specimen (unit: mm).

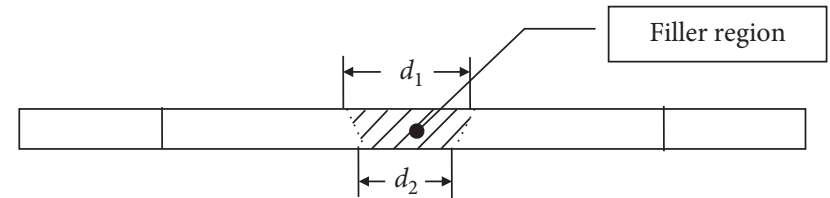

Figure 3: Measurement of the repaired filler region on the specimen (side view).

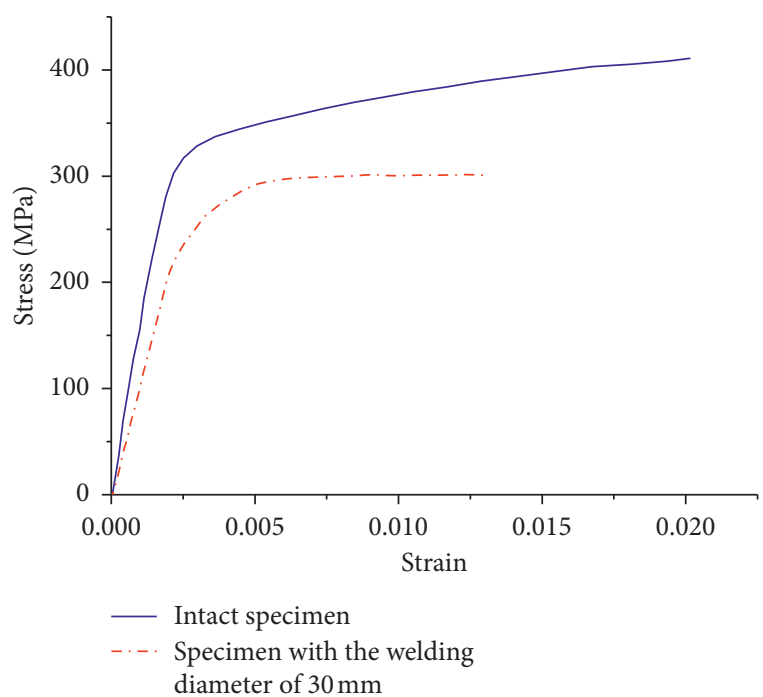

FIGURE 4: Stress-strain responses of the intact specimen and specimen with the welding diameter of $30 \mathrm{~mm}$.

elastic material. The above RVE model contains an inclusion, and the corresponding strain perturbation was taken into account. The strain was divided into intrinsic strain and disturbance strain. The strain constitutive models of matrix and inclusion were established. Based on the Mori-Tanaka equivalent method, the equivalent inclusion model of the castings containing repair welding was established, and the macro-stress-strain tensor expression of the element was obtained. The detailed derivation process was as follows.

As shown in Figure 9, the domain of the RVE model was $\Omega$; its total volume was adopted to be $V$, while a volume of inclusion $V_{1}$ was substituted by the filler material (welding material); and its subdomain was defined as $\Omega_{1}$. The material properties of the filler material and base material were assumed to be statistically homogeneous. The external boundary was supposed to be homogeneous in the deformable body.

The linear elastic relation was satisfied in the condition of small deformation. Since the RVE undertook a volume average stress $\sigma^{0}$, the corresponding strain was $\varepsilon^{0}$. The stress in the filler region was $\sigma_{i}(\Omega)=\sigma_{i j}^{0} x_{j}\left(x_{j}\right.$ are the components of the outward normal of the boundary). The expressions of the volume average stress and strain from microscopic stress and strain were defined by

$$
\left\{\begin{array}{l}
\sigma^{0}=\frac{1}{V} \int_{\Omega} \sigma_{i} d V, \\
\varepsilon^{0}=\frac{1}{V} \int_{\Omega} \varepsilon_{i} d V,
\end{array}\right.
$$

where $\sigma_{i}$ and $\varepsilon_{i}$ are the microscopic stress and strain in a representative volume.

For the assumption of the homogeneous stress boundary condition, the relation between the volume average stress and the strain can be generalized mathematically as

$$
\varepsilon^{0}=\frac{1}{V} \int_{V} C^{0} \sigma d V=C^{0} \frac{1}{V} \int \sigma d V=C^{0} \sigma^{0}
$$

An elastic solution can be obtained for a single inclusion volume of $V_{1}$ embedded in the volume of $V$. According to the Eshelby equivalent inclusion model, because of the existence of an inclusion in the RVE, disturbance will exist in average stress of the base material. The disturbance of the average stress was $\sigma^{\#}$, and the corresponding disturbance strain was $\varepsilon^{\#}$. Thus, the real stress and strain in the base material region were $\sigma^{0}+$ $\sigma^{\#}$ and $\varepsilon^{0}+\varepsilon^{\#}$, respectively.

The stress and strain of the inclusion were different from those of the base material. The differences were $\sigma^{\prime}$ and $\varepsilon^{\prime}$, respectively. Thus, $\sigma^{0}+\sigma^{\#}+\sigma^{\prime}$ and $\varepsilon^{0}+\varepsilon^{\#}+\varepsilon^{\prime}$ were the real stress and strain of the inclusion region. The elastic modulus tensor of the matrix was $\mathbf{M}^{\mathrm{b}}$ and that of the inclusion was $\mathbf{M}^{\mathrm{s}}$. Based on the equivalent inclusion theory of Eshelby, the equivalent inclusion principle was expressed as 


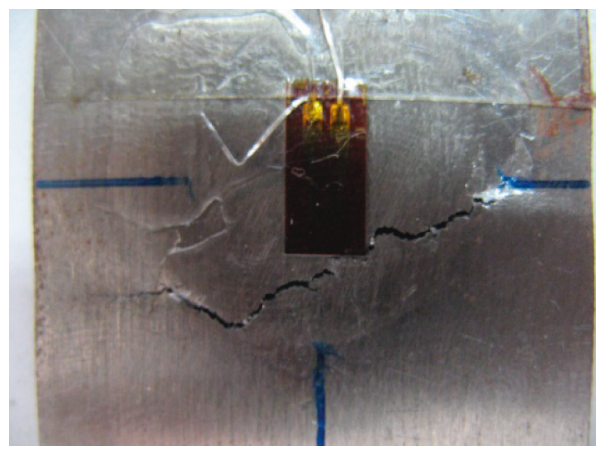

(a)

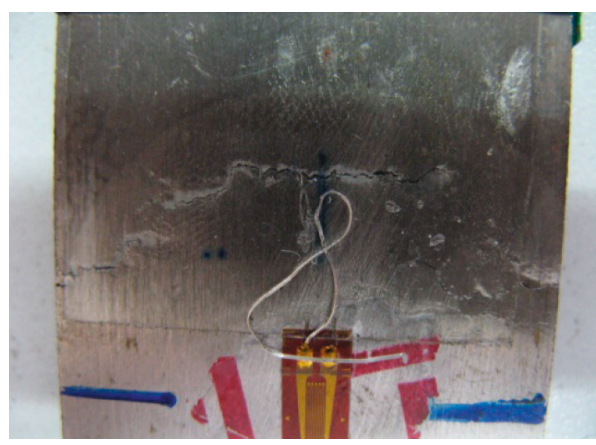

(c)

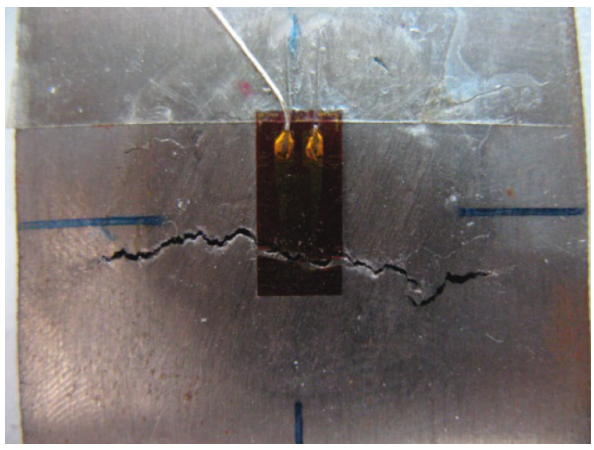

(b)

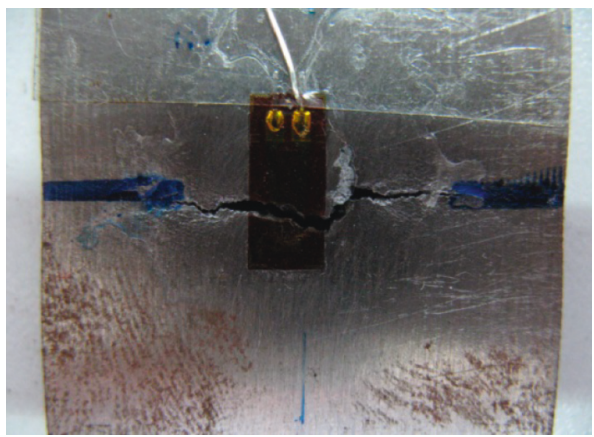

(d)

FIgURE 5: Fracture initiation from the filler region in uniaxial tensile loading.

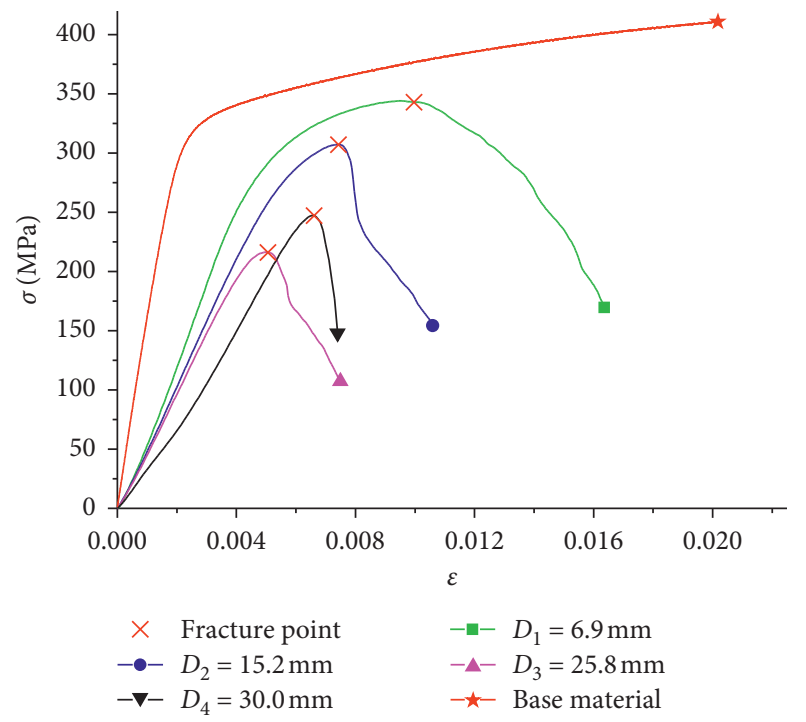

Figure 6: Fracture behaviors of the intact specimen and the specimens with different weld diameters.

$$
\sigma^{0}+\sigma^{\#}+\sigma^{\prime}=\mathbf{M}^{\mathrm{s}}\left(\varepsilon^{0}+\varepsilon^{\#}+\varepsilon^{\prime}\right)=\mathbf{M}^{\mathrm{b}}\left(\varepsilon^{0}+\varepsilon^{\#}+\varepsilon^{\prime}-\varepsilon^{*}\right)
$$

where $\varepsilon^{\#}$ is the disturbance strain of the base material, $\varepsilon^{\prime}$ is the strain difference tensor between the base material and the filler material, and $\varepsilon^{*}$ is the equivalent eigenstrain. Here, $\varepsilon^{\prime}=\mathbf{S} \varepsilon^{*}$, where $\mathbf{S}$ is the fourth-order Eshelby tensor.
Simplifying equation (7), we get

$$
\sigma^{\prime}=\mathbf{M}^{\mathrm{b}} \mathbf{S} \varepsilon^{*}-\mathbf{M}^{\mathrm{b}} \varepsilon^{*}=\mathbf{M}^{\mathrm{b}}(\mathbf{S}-\mathbf{I}) \varepsilon^{*},
$$

where $\mathbf{I}$ is the fourth-order unit tensor.

In the representative volume shown in Figure 9, the volume fraction of inclusion was defined as $\varphi_{1}=V_{1} / V$. For the constant boundary condition, the average stress $\bar{\sigma}$ based on the Mori-Tanaka method [21] was

$$
\bar{\sigma}=\sigma^{0}=\varphi_{1}\left(\sigma^{0}+\sigma^{\#}+\sigma^{\prime}\right)+\left(1-\varphi_{1}\right)\left(\sigma^{0}+\sigma^{\#}\right) .
$$

Solving equations (8) and (9), we obtain

$$
\sigma^{\#}=-\varphi_{1} \sigma^{\prime}=-\varphi_{1} \mathbf{M}^{\mathrm{b}}(\mathbf{S}-\mathbf{I}) \varepsilon^{*}
$$

Comprehensively solving equations (6) to (10), we obtain

$$
\varepsilon^{\#}=-\varphi_{1}(\mathbf{S}-\mathbf{I}) \varepsilon^{*} .
$$

The relationship between the equivalent eigenstrain $\varepsilon^{*}$ and the average strain tensor was obtained by substituting equation (11) and $\varepsilon^{\prime}=\mathbf{S} \varepsilon^{*}$ to equation (7):

$$
\varepsilon^{*}=\mathbf{H} \varepsilon^{0}
$$

where $\mathbf{H}=\left(\mathbf{M}^{\mathrm{b}}-\mathbf{M}^{\mathrm{s}}\right)\left(\left(\mathbf{M}^{\mathrm{b}}-\mathbf{M}^{\mathrm{s}}\right)\left(\varphi_{1} \mathbf{I}+\left(1-\varphi_{1}\right) \mathbf{S}\right)+\mathbf{M}^{\mathrm{s}}\right)^{-1}$.

The effective properties which were represented by the effective stiffness matrix $\overline{\mathbf{M}}$ of the composites, in terms of the average stress and strain, can be defined as

$$
\bar{\sigma}=\overline{\mathbf{M}} \bar{\varepsilon} .
$$




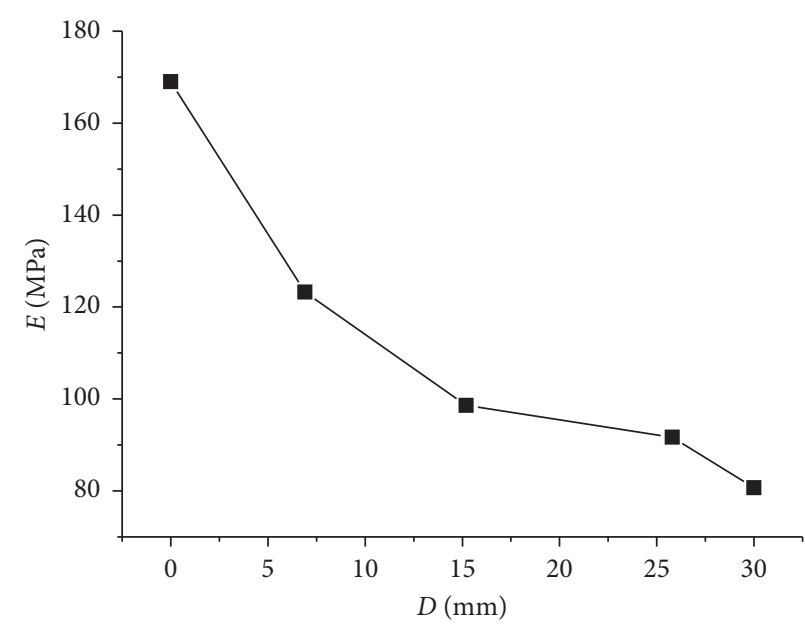

(a)

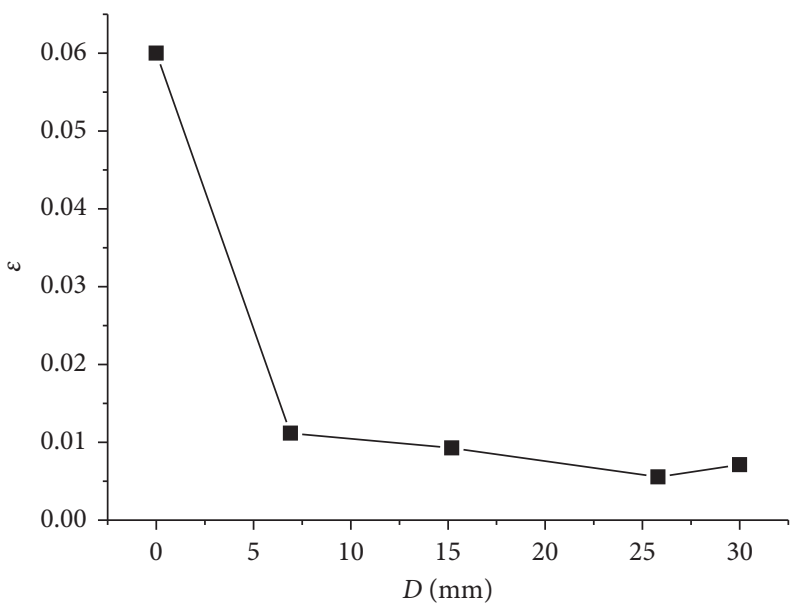

(b)

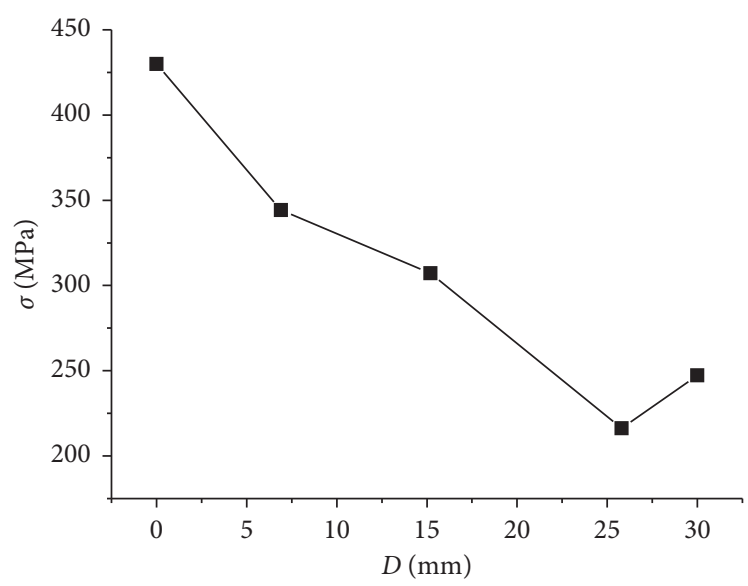

(c)

Figure 7: Effective modulus (a), failure strain (b), and failure stress (c) of specimens with different welding diameters.

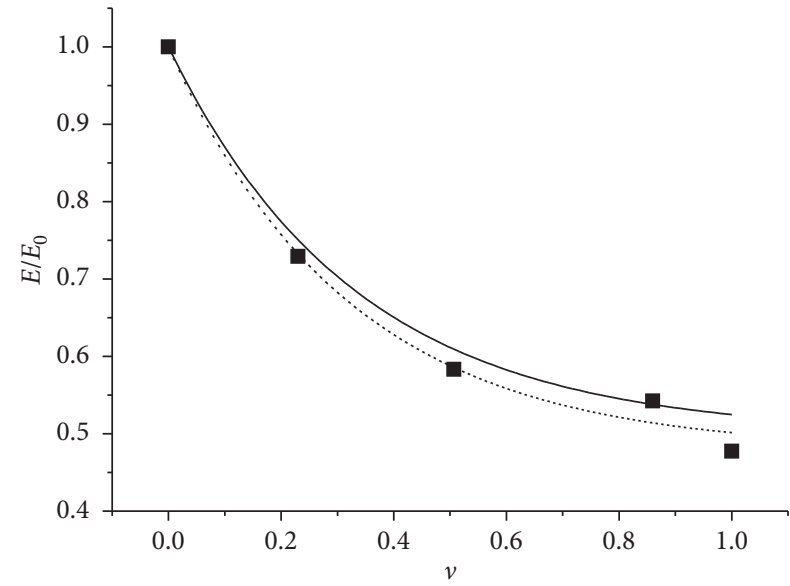

- Experimental data Formula (2)

Formula (3)

FIGURE 8: Relation of effective modulus of the welded specimen with the repair region ratio.

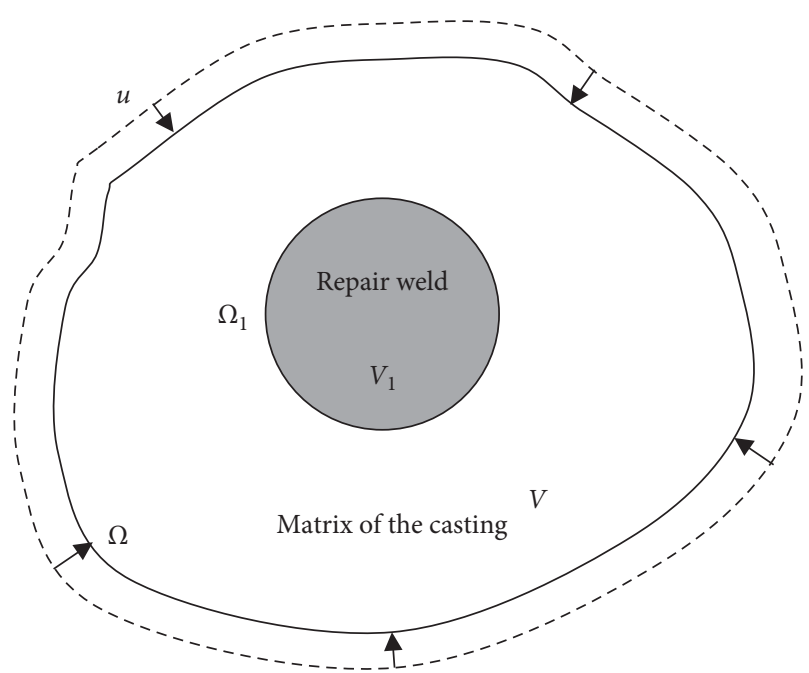

FIGURE 9: Schematic diagram of the RVE: the castings contain repair weld. 


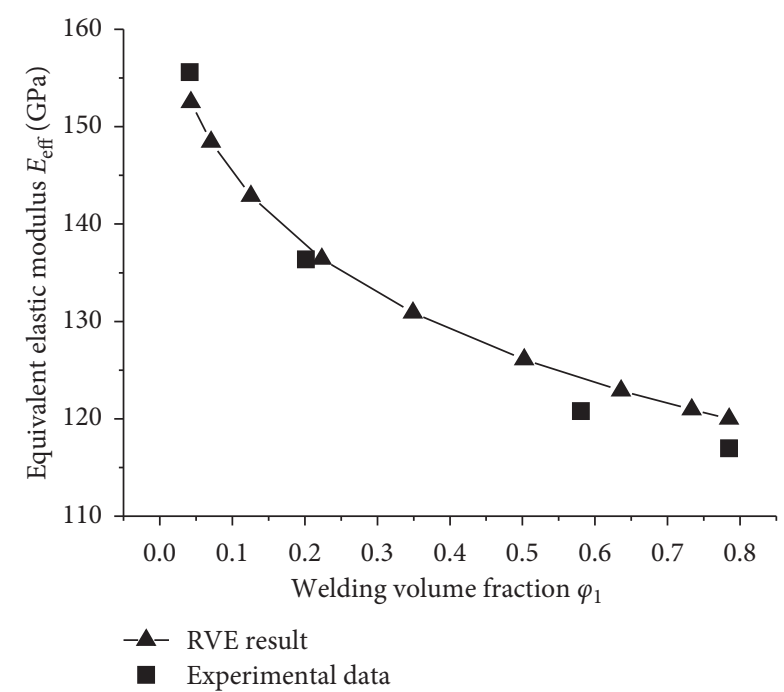

Figure 10: Comparison of experimental data and the prediction results of the RVE model.

According to the Mori-Tanaka method, equation (13) was transformed as

$$
\bar{\sigma}=\overline{\mathbf{M}}\left[\varphi_{1}\left(\varepsilon^{0}+\varepsilon^{\#}+\varepsilon^{\prime}\right)+\left(1-\varphi_{1}\right)\left(\varepsilon^{0}+\varepsilon^{\#}\right)\right] .
$$

Substituting formula (11) into formula (14), the effective stiffness of the RVE was

$$
\bar{\sigma}=\overline{\mathbf{M}}\left(\varepsilon^{0}+\varphi_{1} \mathbf{I} \varepsilon^{*}\right)
$$

The macro-stress-strain properties of nodular cast iron can be deduced by the equivalent inclusion method. The dimensions of $V_{1}$ (round repair welding volume) along the Cartesian coordinate system $x_{1}$ and $x_{2}$ were $a_{1}=a_{2}=a$, and the thickness was $a_{3}$. The Eshelby tensor $\mathbf{S}$ is considered as a constant given by

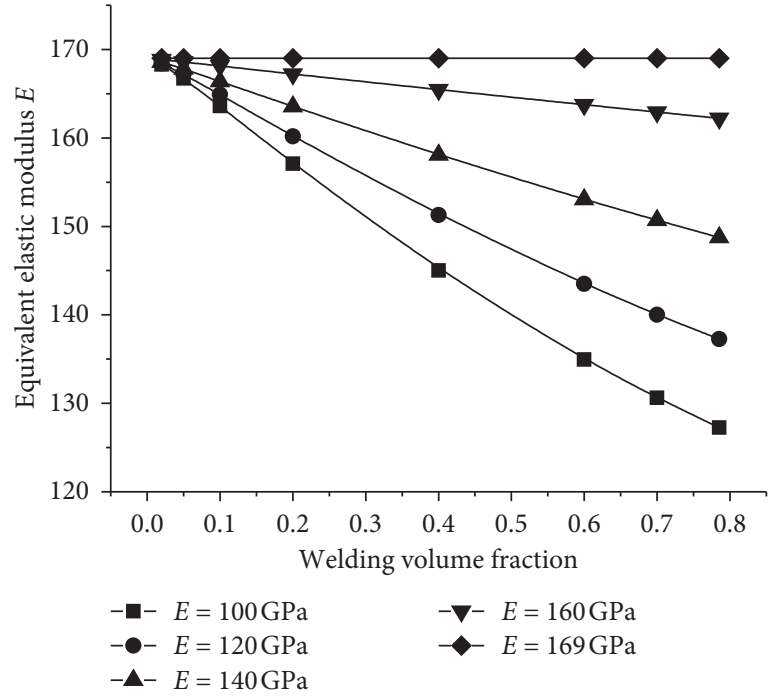

FIGURE 11: Influence of the filler material property and weld volume fraction on equivalent elastic modulus.

$$
\begin{aligned}
\mathbf{S}_{i j k m}= & \frac{1}{16 \pi(1-v)}\left\{2 \delta_{i j} \delta_{k m}\left[a_{K}^{2} \mathbf{I}_{I K}-(1-2 v) \mathbf{I}_{I}\right]\right. \\
& \left.+\left(\delta_{i k} \delta_{j m}+\delta_{i m} \delta_{j k}\right)\left[\left(a_{I}^{2}+a_{J}^{2}\right) \mathbf{I}_{I J}+(1-2 \nu)\left(\mathbf{I}_{I}+\mathbf{I}_{J}\right)\right]\right\},
\end{aligned}
$$

where the capital letter subscripts $I, J$, and $K$ mean their values equaled $i, j$, and $k ; \mathbf{I}_{I}=\mathbf{I}_{i}, \mathbf{I}_{I K}=\mathbf{I}_{i k}, \mathbf{I}_{I J}=\mathbf{I}_{i j}$, and $\mathbf{I}_{J}=$ $\mathbf{I}_{j}$ were obtained through Routh formula [22], and their values were given by integrals. The tensor expression of the elastic field with the equivalent mechanical properties to the casting with welding was established:

$$
\left\{\begin{array}{l}
\mathbf{I}_{i}=2 \pi a_{1} a_{2} a_{3} \int_{0}^{\infty} \frac{d s}{\left(a_{i}^{2}+s\right) \sqrt{\left(a_{1}^{2}+s\right)\left(a_{2}^{2}+s\right)\left(a_{3}^{2}+s\right)}} \\
\mathbf{I}_{i j}=2 \pi a_{1} a_{2} a_{3} \int_{0}^{\infty} \frac{d s}{\left(a_{i}^{2}+s\right)\left(a_{j}^{2}+s\right) \sqrt{\left(a_{1}^{2}+s\right)\left(a_{2}^{2}+s\right)\left(a_{3}^{2}+s\right)}}
\end{array}\right.
$$

where $s$ is the integration variable.

\section{Influence Factors of Effective Modulus}

5.1. Influence of Volume Fraction. The volume fraction of inclusion was one of the important factors affecting the equivalent mechanical properties of castings. The repair welding size can be respected by the welding volume fraction. Here, the material properties of matrix and inclusion in the RVE element were the same as those of the test. The volume fractions of the specimens in the tension tests were $0.02,0.05,0.1,0.2,0.4,0.6,0.7$, and 0.7854 . Substituting these values into the tensor matrix $\overline{\mathbf{M}}$, the effective mechanical properties of repaired cast iron with different welding volume fractions were expressed by equation (16). The theoretical results were compared with the experimental results, as shown in Figure 10. The theoretical solutions were in good agreement with the experimental results. The effective modulus was closer to the modulus of the base material when the welding volume fraction was smaller.

5.2. Influence of Filler Material Properties. Besides the volume fraction, the filler material property was another factor that influenced the effective mechanical property. So, for the 
same model, while the property of the filler material varied, the effective mechanical property was different. The elastic modulus of the filler material with five grades was analyzed, the modulus of the base metal remained unchanged, and the modulus of the filler metal was selected as $100 \mathrm{GPa}, 120 \mathrm{GPa}$, $140 \mathrm{GPa}, 160 \mathrm{GPa}$, and $169 \mathrm{GPa}$ (its value depends on the filler material). Figure 11 shows the changes of equivalent elastic modulus with different volume fractions $\varphi_{1}$ and filler material properties.

The higher material property of the filler material results in a slower decrease rate of equivalent elastic modulus in a specified volume fraction. Therefore, when selecting electrode materials for repair welding in engineering, in order to reduce the influence of the material property and welding volume fraction on the filler material, the filler material with parameters similar to the base material parameters should be selected.

\section{Conclusion}

(1) Fracture initiated in the filler region in uniaxial tensile loading, and the modulus, strength, and ductility tended to decrease with the weld diameter increase. The postyield hardening phenomenon of nondefected cast iron disappeared after repair welding. The effective modulus of repaired cast iron decreased with the repaired region ratio according to the rule of negative exponent.

(2) Based on Eshelby equivalent inclusion theory, a model for estimating macroscopic effective modulus of repair welding castings was established. Comparing with the experimental results, the predictions were in good agreement with the experimental results.

(3) The volume fraction of repairing and the filler material property were the two major factors for the effective modulus of repaired casting. The effective modulus was closer to the modulus of the base material when the welding volume fraction was smaller. The filler material with properties similar to base material properties should be selected as far as possible to restore the effective modulus of repaired casting.

\section{Data Availability}

The data used to support the findings of this study are available from the corresponding author upon request.

\section{Conflicts of Interest}

The authors declare that they have no conflicts of interest.

\section{Acknowledgments}

This project was supported by the National Natural Science Foundation of China (Grant no. 51875460) and the Aviation Power Foundation (Grant no. 6141B090320).

\section{References}

[1] K. M. Sigl, R. A. Hardin, R. I. Stephens, and C. Beckermann, "Fatigue of 8630 cast steel in the presence of shrinkage porosity," in Proceedings of the 57th SFSA Technical and Operating Conference, Steel Founders' Society of American, Chicago, IL, USA, 2003.

[2] W. Zhao, Z. Zhou, X. Yu et al., "Effect of shrinkage porosity on mechanical properties of QT400-18L casting," Physical Testing and Chemical Analysis, Part A (Physical Testing), vol. 47, pp. 546-549, 2011.

[3] Y. Yang, Q. Wu, Y. Wang, Q. Weiyang, and L. Kuan, "Dynamic characteristics of cracked uncertain hollow-shaft," Mechanical Systems and Signal Processing, vol. 124, pp. 36-48, 2019.

[4] J.-L. Desir, "Examples of repair welding of heavy machinery subject to breakage due to low frequency alternating stresses," Engineering Failure Analysis, vol. 8, no. 5, pp. 423-437, 2001.

[5] S. K. Albert, C. R. Das, V. Ramasubbu, A. K. Bhaduri, S. K. Ray, and B. Raj, "In situ repair welding of steam turbine shroud for replacing a cracked blade," Journal of Materials Engineering and Performance, vol. 11, no. 3, pp. 243-249, 2002.

[6] W. Liu, F. Li, F. Yan, and H. Wang, "Influence of random shrinkage porosity on equivalent elastic modulus of casting: a statistical and numerical approach," China Foundry, vol. 14, no. 2, pp. 108-120, 2017.

[7] W. C. Wang, "Creep fracture characteristics of weld-repaired cast Ti-6Al-4V," Metallurgical Transactions, vol. 5, no. 3, pp. 565-572, 1974.

[8] G. B. Hunter, F. S. Hodi, and T. W. Eagar, "High cycle fatigue of weld repaired cast Ti-6AI-4V," Metallurgical Transactions A, vol. 13, no. 9, pp. 1589-1594, 1982.

[9] C. Y. Su, C. P. Chou, B. C. Wu, and W. C. Lih, "Plasma transferred arc repair welding of the nickel-base superalloy IN-738LC," Journal of Materials Engineering and Performance, vol. 6, no. 5, pp. 619-627, 1997.

[10] Q. G. Wang, D. Apelian, and D. A. Lados, "Fatigue behavior of A356-T6 aluminum cast alloys. Part I. Effect of casting defects," Journal of Light Metals, vol. 1, no. 1, pp. 73-84, 2001.

[11] E. Smith, "The stress associated with a crack in a repair weld," International Journal of Fracture, vol. 53, no. 4, pp. 59-62, 1992.

[12] C. Zhang, X. Song, P. Lu, and X. Hu, "Effect of microstructure on mechanical properties in weld-repaired high strength low alloy steel," Materials \& Design (1980-2015), vol. 36, pp. 233-242, 2012.

[13] H.-j. Liu and H.-j. Zhang, "Repair welding process of friction stir welding groove defect," Transactions of Nonferrous Metals Society of China, vol. 19, no. 3, pp. 563-567, 2009.

[14] B. Younise, A. Sedmak, M. Rakin et al., "Micromechanical analysis of mechanical heterogeneity effect on the ductile tearing of weldments," Materials \& Design, vol. 37, pp. 193201, 2012.

[15] A. Venugopal, K. Sreekumar, and V. S. Raja, "Effect of repair welding on electrochemical corrosion and stress corrosion cracking behavior of TIG welded AA2219 aluminum alloy in 3.5 Wt Pct $\mathrm{NaCl}$ solution," Metallurgical and Materials Transactions A, vol. 41, no. 12, pp. 3151-3160, 2010.

[16] S. Katsas, J. Nikolaou, and G. Papadimitriou, "Microstructural changes accompanying repair welding in $5 \mathrm{xxx}$ aluminium alloys and their effect on the mechanical properties," Materials \& Design, vol. 27, no. 10, pp. 968-975, 2006. 
[17] K. Shankar and W. Wu, "Effect of welding and weld repair on crack propagation behaviour in aluminium alloy 5083 plates," Materials \& Design, vol. 23, no. 2, pp. 201-208, 2002.

[18] H. Durmuş, "Mechanical properties and corrosion behaviour of MIG welded 5083 aluminium alloy," Materials Testing, vol. 53, no. 6, pp. 356-436, 2011.

[19] M. P. Nascimento and H. J. C. Voorwald, "Considerations about the welding repair effects on the structural integrity of an airframe critical to the flight-safety," Procedia Engineering, vol. 2, no. 1, pp. 1895-1903, 2010.

[20] J. D. Eshelby, "The determination of the elastic field of an ellipsoidal inclusion and related problems," Proceedings of the Royal Society of London, Series A: Mathematical and Physical Science, vol. 241, no. 1226, pp. 376-396, 1957.

[21] T. Mori and K. Tanaka, "Average stress in matrix and average elastic energy of materials with misfitting inclusions," Acta Metallurgica, vol. 21, no. 5, pp. 571-574, 1973.

[22] E. J. Routh, "Theorems on the attraction of ellipsoids for certain laws of force other than the inverse space," Philosophical Transaction of the Royal Society: Mathematical, Physical and Engineering Sciences, vol. 168, pp. 897-950, 1895. 


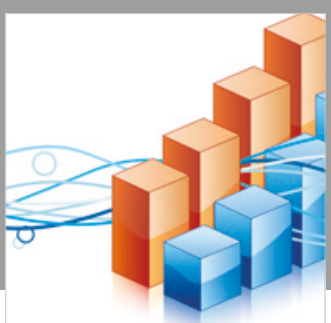

Advances in

Operations Research

\section{-n-m}
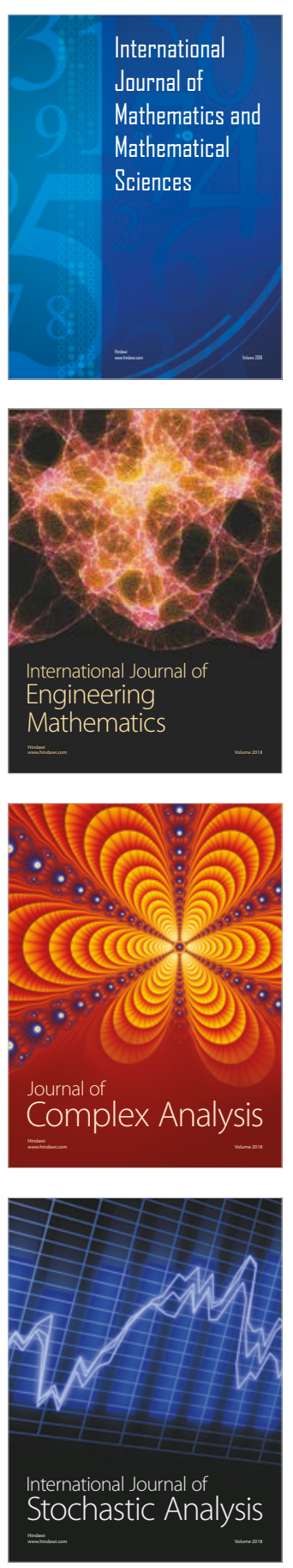
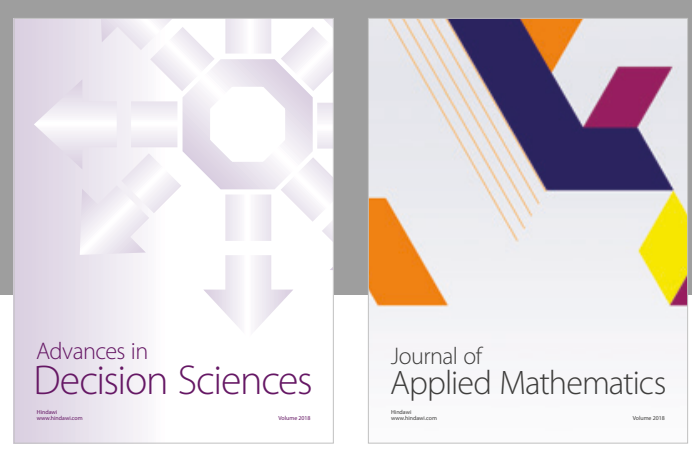

Journal of

Applied Mathematics
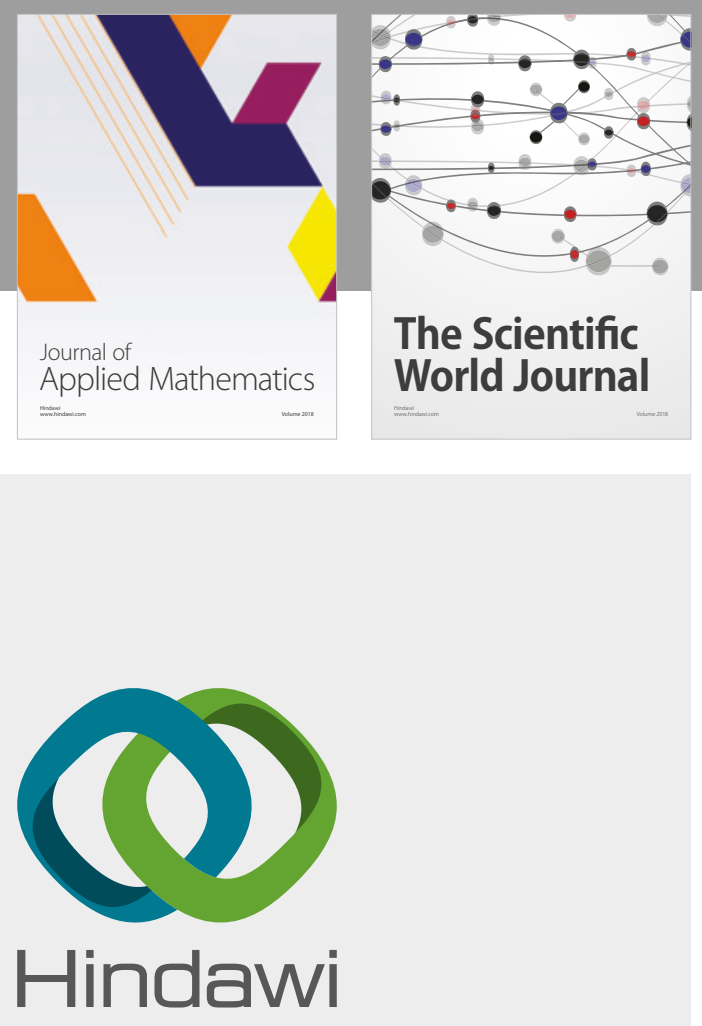

Submit your manuscripts at

www.hindawi.com

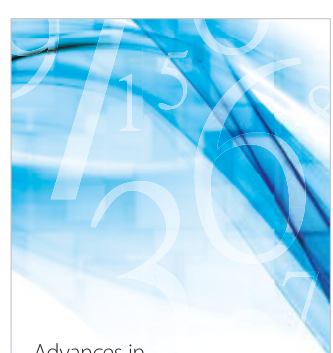

Advances in
Numerical Analysis
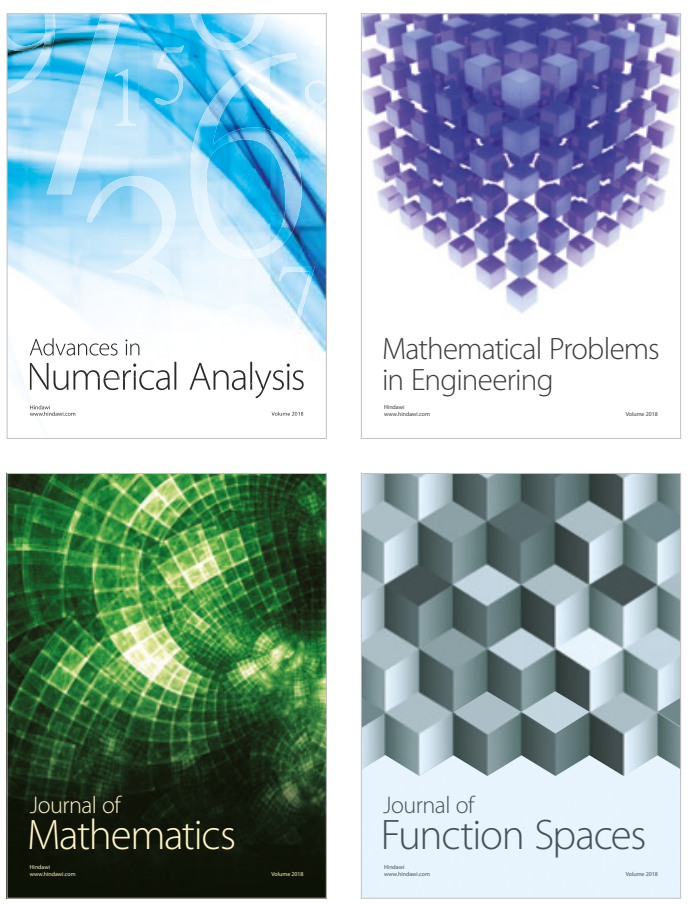

Mathematical Problems in Engineering

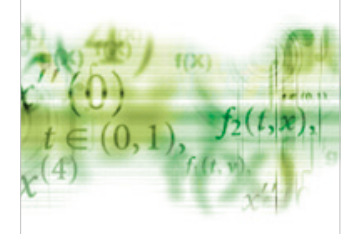

International Journal of

Differential Equations

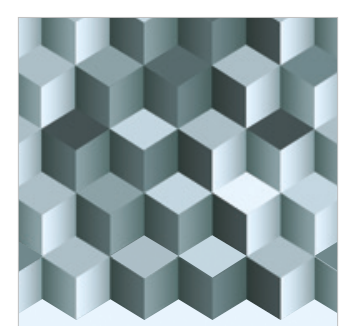

Journal of

Function Spaces

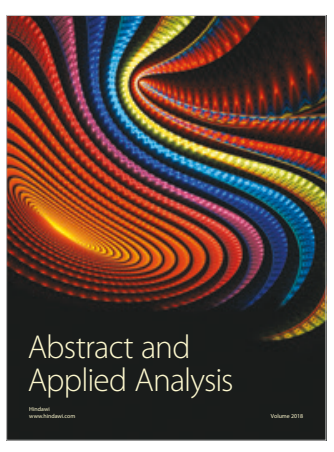

The Scientific

World Journal

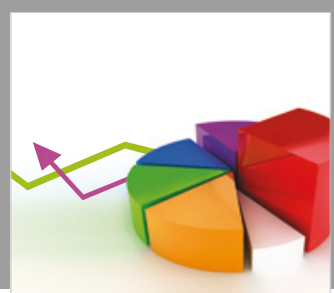

Journal of

Probability and Statistics
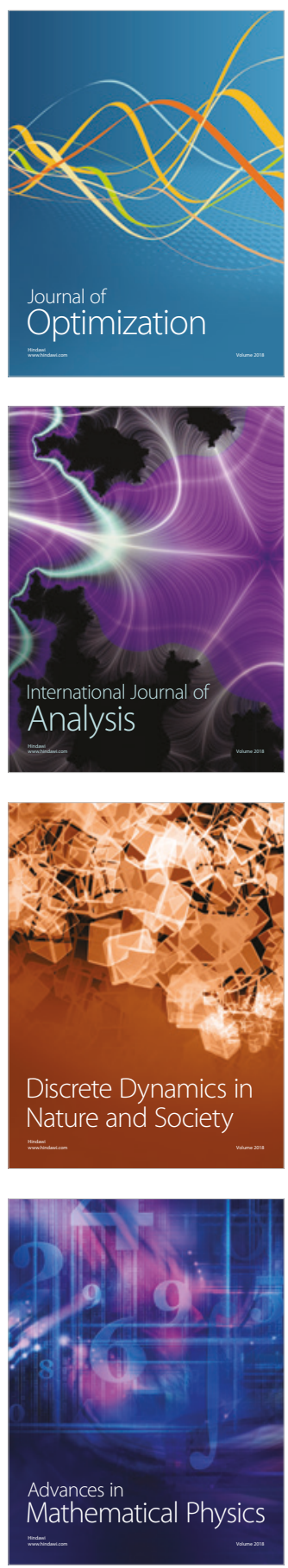